\title{
Automatic Detection of Discourse Structure by Checking Surface Information in Sentences
}

\author{
Sadao Kurohatsia and Malioto Nagao \\ Dept. of lifectrical kngineering, Kyoto University \\ Yoshida hommachi, Saligo, Ryoto, 606, Japan
}

\begin{abstract}
In this paper, we propose an antomatic method for detecting discourse structure using a varicty of clues existing in the sulface information of sentences. We have considered three uypes of clue information: alue expressions, occurbence of identical/symonyurous words/plumases, and simitarity between two sentences. Fxperimental results have slowe that, in the case of scientific and lechnical texts, considerahte part of llor discontse structure can be astumatod by incorporation

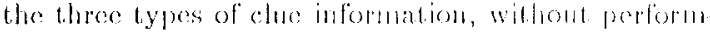
ing sentence understanding processes which reguires giving knowledge to compunters.
\end{abstract}

\section{Introduction}

to understand a text or dialogue, one must track the discourse strueture (DS), spectlying how sontence are combined and what lind of relations (colnerences relations) they have. Worli on DS has mainly focused on such canestions as what kind of knowledgestonld be employed, and how inference may be perforened hased on such linowledge (e.g., Cirosm and sidher 1986; Ilobbe 1985; Kadrozny and Jensen 1991). However, by eximllining the current status of work hot th on antomatice extraction and on mantal coding of knowledge, letailed knowledge with broad coverage availabilily lo computers is unlikely to be constructed for the present. On the ofther hand, recent rapicl increase ia the anount of on-line texts has foreed us to antalyze not only fordined sentences but also discontses usitge present avaltathe knowledget.

We propose here an antomatio mothod for costimat. ing dos in scientific and lechuical toxts by a variely of keys existing in the surface information of sentences.

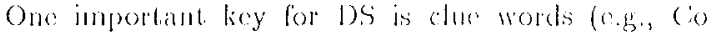
hon 1984; (irosz and Sidner 1986; Rechman 1985) fubluermore, we have considered twe more importan ches. One is the occurrence of identical/synonymons words/phrases for delecting topic chaning or topicdominant chaining relation (Polanyi and Scha 1981); the other is a certain similartity betwern two sentences

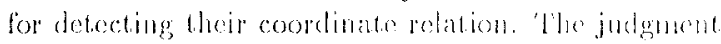
based on such clue information is not absolute lant just. probable. Therefore, we have incorponated the above mentioned three lactors into one evaluation meatsure to estinate the most plansilite 1)S.

\section{Discourse Structure Model and Coherence Relations}

Studies of DS have been reported by a large number of reseatchers (c.g., Cohen 1984; Dalgren 1988; Grosz and Siduer 1986; Iloblos 1985; Mann 1084; Polanyi and Schn 1984; Reichman 1085; Zadrozny and Jonsen 1991). What has been commonly suggested is that 130 OS resulting from the recursive embedding and sefuencing of discomse muts has the form of a tree (disconrse history parse tree). However, there has been a. variety of definition for discourse units, constituents of the tree, and colerence rolations. In this research we lave adopted the simplest model in the interest of focusing on how to detect IDs automatically. In our model, rach sentence is considered a discourse nuit, and rach node of the discourse history parse tree is a sentence and each link a colnerence relation, ${ }^{1}$

Colorence retations existing in at text, as Reichman (1985) pointed ont, greatly dejend on the gente of the text.; narrative, argunent, news article, conversation, and scientific report. Among a number of the coher. cree relations suggested so far, we solected the following sel of the relations which accounted for intuitions concerning our target texts, namely scientific and techtrical lexts (Si denotes the former sentence and $\mathrm{Sj}$ the lat.ter).

List: Si and Sj involve the same or similar events or states, or the same or simitar important con.

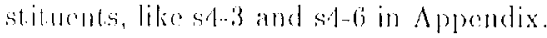

Contrast : Si and $\mathrm{Sj}$ involve contrasting eventis or shatcs, or contribiting important constituents.

Topic chaining : Si and Sj have distinct predications about the sane topice, like sl-13 and s1-19.

Topic-doninant dnaining : A dominant constituent atsat from a given topic in Si becomes a topic in Sj, like st-1 and s st-5.

Glaboration : Sj gives details about a constituent introduced in si, like st-16 and s1-17.

Reason : $\mathrm{Sj}$ is the reason for $\mathrm{S} \mathbf{i}$, like st-13 and s1-14.

Canse: $s$ j occurs as a result, of $\mathrm{Si}$, like sl-17 and s!- 18 .

'Al present, we regard a sentemee marked off by a period as a diseontine tunt. Colierence relations are existing also between datuses io a semteme. We thibk our approall examining surface clus iufomation can be adapted to extract their relations, and wo intend to extend one system to handle them. 


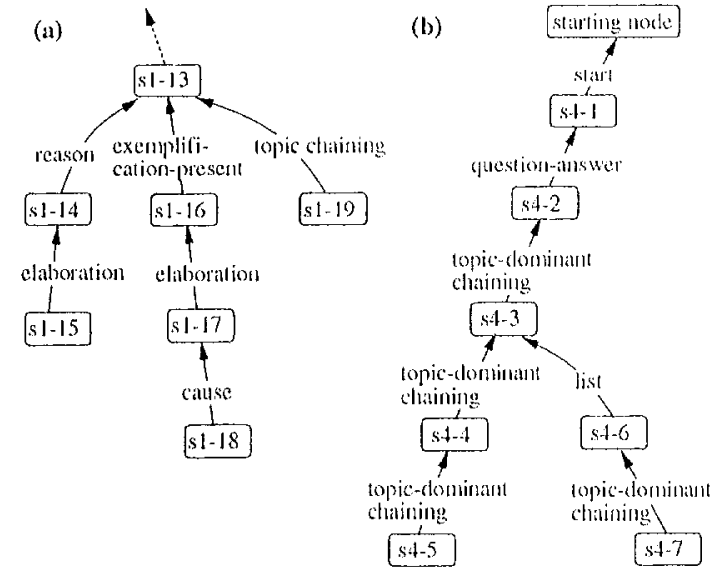

Figure 1: Examples of discourse structures.

Change: The event or state in Si changes in Sj (ustally as time passes).

Exomplification-present: An cxanple of the event, state or constituent in $\mathrm{S} i$ is introduced in sj, like sl-13 and $\mathrm{s} 1-16$

Exemplification-explain : An example of the creath, state or constituent in $\mathrm{Si}$ is explanined in $\mathrm{Sj}$.

Question-answer : $S \mathrm{j}$ is the answer to the cunestion in $\mathrm{Si}$, like st-1 and $\mathrm{s} t-2$.

The DSs for the sample text in Appondix is shown in Figure 1.

As in many previous approaches, we also make the following assumption in the DS model: an now sentence coming in can be connected to the node on the right most erlge in the DS tree (hereater, wo call a new sentence an NS, and a possible connected sentence on the right edge in the DS tree a CS: Pigrare 2). 'P'lis means that, after detailed explanations for one topic terminate, and a new topic is introduced, details of the old topic are lidden in inner nocles and ane no longer referred to.

\section{Automatic Detection of Dis- course Structure}

\subsection{Outline}

Considering our DS model, wat he ISS analysis should do is clear; for each NS, it t.ries to find the correct CS and the correct relation between them. In order to estimate them, we have directed our allention to three types of clue information: 1) clue expressions indicating some relations, 2) occiirrence of identical/synonymous words/phrases in topic chaining or topic-dominant chaining relation, 3) similarity between two sentences in list or contrast relation. By the? method described later wo can transform such information into reliable scores for somo relations. As an

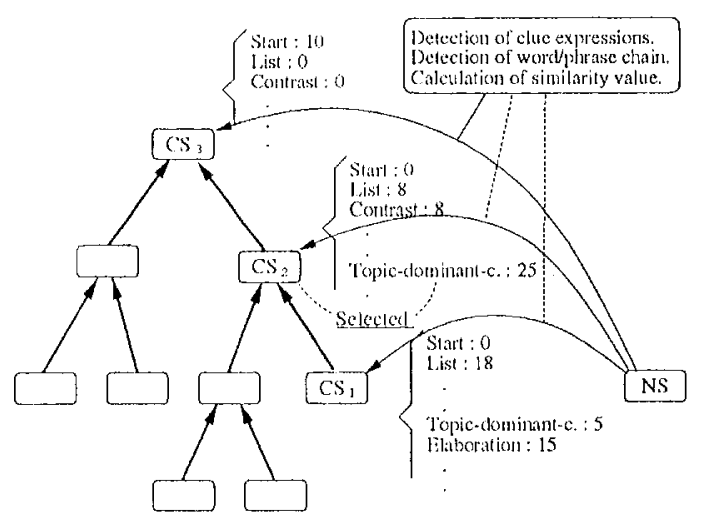

Figure 2: Ranking rolations to CSs by three types of clue information.

NS comes in, for each CS we calculate reliable scores for all relations by examining the above three types of clues. As a finial result, we choose the CS and the relation having lie maximum reliable score (Figure 2).

As an intial state a DS has one node, starting node. We always give a certain score for the special relation, start, between an NS and the stating node. When any offer rolation to any Cs does not have larger score for an NS, it is connected to the starling node by stant retation. This means that the NS is the starting scrutence of a new large segment, like paragraph or section, in the DS.

\subsection{Detection of Clue Expressions}

We prepared heuristic rules for finding clue oxpressions by pattern matching and relating them to proper relations witl reliable scores. $A$ rule consists of the fol lowing parts:

- condition for rule application:

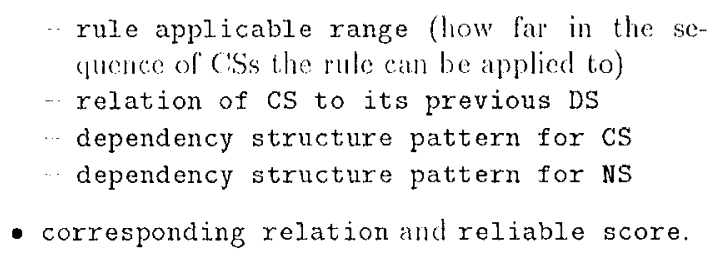

- corresponding relation and reliable score.

Patterns for CS and WS are matelied not for word secunences but for dependency structures of both senlentes." Wo twe a powerful pattern matching facility for dependency structures, where a wild card matching any partial clependency structure, regular expressions, ANI), OR-, NOT'operators, etc. are available (Murata and Nagao 1993). We apply each rule for the pair of a CS and an NS. If the condition of the rule is salisfind, lhe specified reliable score is given to

\footnotetext{
${ }^{2}$ luput to our system is a sequence of parsed sentences, depenclency structures, by our developed parser (K'uroliashi and Nagao 1992al). In Jitpanese the dependency structure of a senance consists of head/modifier relations between bunsetsus, ench of which is composest of at content word and suffix words.
} 
Rnule-1
range: 1
relation of CS : *
CS : *
NS : NAZIi-NARA-
(because)

relation : reason

score: : 20
Table 1: Fxamples of licuristic rules for cluc expressions.

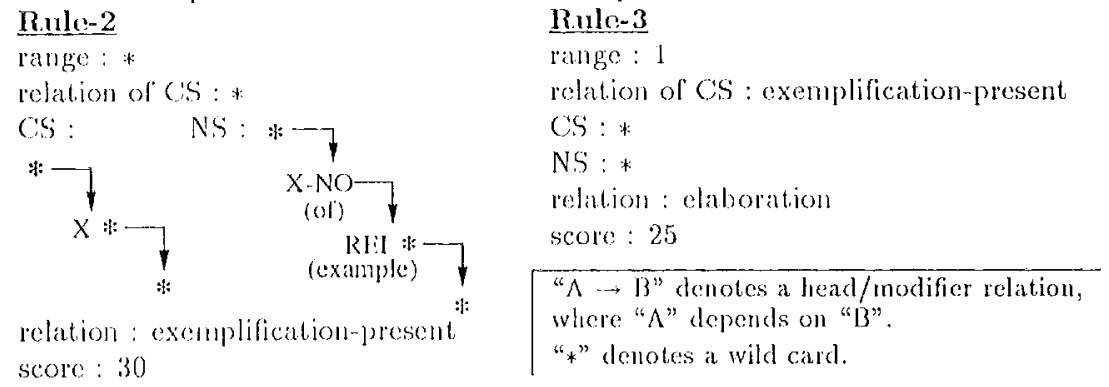

the corresponding relation between the (s) and the NS.

I'or example, Rule-1 in 'fahle 1 gives a score to the reason relation between two adjoining sentences (note the rule applicable range is 'l') if the NS starts with the expression "NA\%1-NARA (because)". Rule2 in lable 1 is applied not only for the neighboring (si but also for farther CSs, by specifying the occurence of identical words (" $X$ ") in the condition. Wo also caul specify the relation of CS to its previous DS as a condition, like Rule-3 in 'Table 1. This mule considers the fact that when some examples are introduced by exemplification-present relation, detated explanations for them often follow.

\subsection{Detection of Word/Phrase Chain}

In genemal a sentence can be divided into lwo parts; a topic part and a non-topic part. When ho sentences are in a topice chaining rolation, the sanke topic is maintained through then. 'Therefore, the oscurrence of identical/synonymous words/phlarases (hor word/phrase chain) in topie parts of two sentences supports this relation. In the case of topic-dominant. chaining relation, a dominant constituent introduced in a non-topic part of a prior sentence becomes a topic in a succeding sentence. So, the word/phrase chain from a non-topic part of a prior sentence to a topic part of a succeding sentence supports this rolation.

thowever, since there are many clues for an NS supporting other relations to sone CSis, we mest not. only find such word/phrase chains but also give some reliable score to topie chaning or topic-dominant daining relation. In order to do this, we give scores 10 words/phrases in topic and non-topic palts according to the degree of their importance in senteness; wo also give scores to the matching of identical/symonymous words/phratses according to the degree of their agrenment. Then we give these relations the sum of the scores of two chained words/phases and the score of their matching (Fignte 3).

All of these are done by applying lules consisting of a paterere for a partial depentency strueture and a score. for example, by Rule-a and b in Talyle 2, words in a phase whose head word is followed by a topic marking postposition "WA" ate given some scores as topic

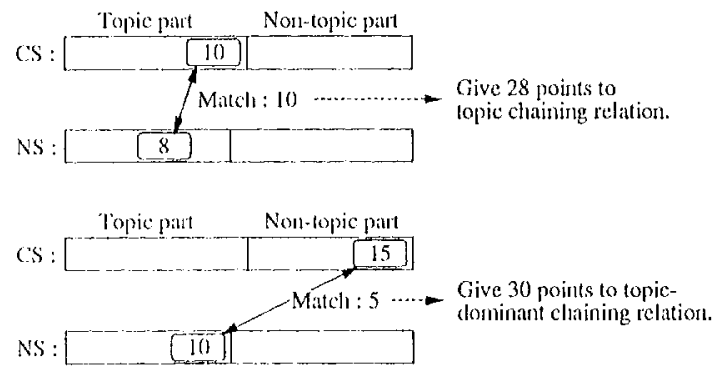

Figure 3: Scores for topic/topic-dominant chaining.

parts. A worl in a non-topis part in the sentential style, ". (i A ARU(whele is ...)" is given a large score by Rule-c in lable 2 because this word is an important new information in this sentence and topic-dominant daining relation involving it often occur. Matching of phrases like " $A$ of $B$ " is given a larger score than that of word like "A" alone by Rule-d and e in 'l'able 2. ${ }^{3}$

\subsection{Calculation of Similarity between Sentences}

When lwo sentences have list or contrast relation, they luve a certain similarity. Ilowever, their similarity cannot be detected by rules like the above which sce relatively small blocks in sentences, because it is not the simple similarity but the similarity in the sequence of words and their grammatical structures as a whole. In order to measure such a similarity, we extended our (ynamic programming method for detecting the scope of a coordination in a sentence (Kuroliashi and Nagao 1092b). 'This method cun calculate the overall sinularity value between two word-strings of arbitrary lengths. lirst, the similarity valuo between two worels are calculated aceording to exact matehing, matching of their parts of speech, and their closeness in a thesantus diclionary. 'Then, the similarity value betwen two word-strings are calculated roughly by combining the similarity values between words in the two word-

\footnotetext{
30no diflicult problem is that authors often use subtly different expressions, mot identival worls/pluases, for such chains. While some of them can be caught by using a thesaurus and by rules lilie liule-f in 'lables 2 , there is a wirle range of variety in their diflerences. 'lheir complete treatment will be a target of our fulture work.
} 
Table 2: Examples of rules for topic/non-topic parts and matching.

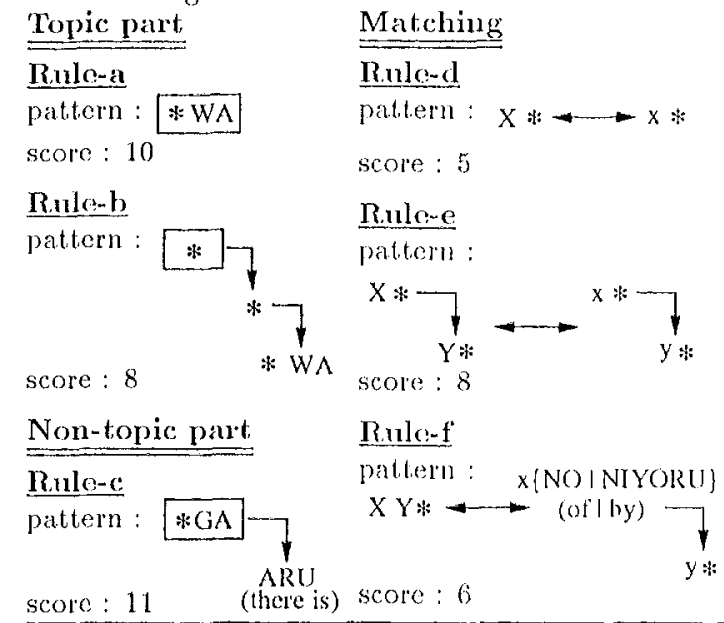

As for rules for topic/non-topic parts, the score is given to the bunsetsu marked by a square. As for rules for matching, " $X$ " and " $\mathrm{x}$ " denote identical words or synonymous words from this Japanese thesaurus, "Bummi Gol Ilyou". So do "Y" and " $y$ ".

st.rings.

While originally we calculated the similatity value between possible conjuncts in a sentence, here we calculate the similarily value hetween two sentences, a $6 \mathrm{~S}$ and an NS, by this method. This can be done simply by connecting two sentences and calculating the similarity value between two initative conjuncts consisting of the two sentences. We give the normatized similarity score between a CS and an NS (divided by their average length) to their list and contrast rolations as a reliable score.

\section{Experiments and Discussion}

Experiments of detecting DS were done for nine sections of an article of the popular science journal, "Science", translated into Japanese (Vol.17,No.12 "Advanced Computing for Science", the original is "Scientific American" Vol.257,No.4). For the first three sections, we wrote rules for clue expressions and word/phrase chains, and adjusted their parancters through experimentation. Then wo analyzed the remaining six sections by alding rules only for the clue expressions. The analysis results are shown in Table 3. Hore the NSs in the text were dassified accord ing to their correct relations in combecting to propere CSs. "Suceess" means that the correct relation and CS were detected for an NS (correct rolations and CSs were judged by authors).

Table 3 shows that many ches oxist in a text so llat much of the DS can be guessed without aletaled knowledge. In order to construct rules for dhe expressions with broad coverage, wo need to consult and andyze a large volume of lexts. However, in most cases rules
Table 3: Analysis rosults.

\begin{tabular}{|c|c|c|c|c|}
\hline \multirow[t]{2}{*}{ Relation } & \multicolumn{2}{|c|}{$\begin{array}{c}\text { Training text } \\
(3 \text { sections })\end{array}$} & \multicolumn{2}{|c|}{$\begin{array}{l}\text { Test Text } \\
\text { (6 sections) }\end{array}$} \\
\hline & Success & & Success 1 & ilure \\
\hline Start & 7 & 1 & 6 & $\overline{2}$ \\
\hline list & 10 & 1 & 15 & 2 \\
\hline Contrast & 6 & 1 & 2 & 2 \\
\hline Topic chaining & 13 & 1 & 21 & 5 \\
\hline Topic-dominant c. & 10 & 1 & 37 & 14 \\
\hline Elaboration & 9) & 1 & 9 & 1 \\
\hline Reason & 3 & 0 & 1 & 0 \\
\hline Cause & 2 & 0 & 6 & 0 \\
\hline Change & 3 & 0 & 0 & 0 \\
\hline Jixenp -present & 1 & 0 & 0 & 0 \\
\hline Exenp-explain & 3 & 0 & 2 & 0 \\
\hline Question-answer & 1 & 0 & 1 & 0 \\
\hline $\begin{array}{l}\text { Total } \\
\text { (Success ratio) }\end{array}$ & & & 100 & $\begin{array}{r}26 \\
79 \%)\end{array}$ \\
\hline
\end{tabular}

for clue expressions can be written exclusively so that they scarcely interfere with each other. In our experiments, added rules for the remaining six sections had no influence on the andysis of the first three sections.

The text from s1-13 to st-19) in Appendix was transformed to the structure in Figure 1 -il as follows.

S1-14: the clue expression, "I)AKARA-DFARU" which means "hits is becanse".

s1-15: the clue expression, "-WAKL-1)EARU".

s1-16: the cho expression "example of $X$ ".

s-17: the heuristic rule supporting elaboration relalion after excmplificalion-present relalion

S1-18: the clue expression "(SONO)KEKKA(-WA), (tho result is)" which corresponds to "lead" in semantics.

S1-19: the chat of "synthetic approach".

The text from st-1 to st-7 in Appendix was also transformed to the structure in figure 1-1) as follows.

44-2: the clue expressions: "KA" (a sulfix indicating an interrogalive sentence) in st-1 and "(the) answer "in $s 4-2$.

44-3: the chain of "double star".

s4-4: the chain from "shrinli" in s4-3 to "this process" in st-1 (some expressions like "this process" are regarded as matching any verb in a previous scrlence).

44-5: the chain of "unclear fusion".

s4-6: the large sinilarity value between s4-3 and st-6 and the clue expression "similarly".

44-7: this NS could not be analyzed correctly. List relation will silf was dedected incorrectly because of lheir similarity value.

In st-6 and st-7, while the same word "heal" is used in linglish, the prior "hent" was translated into "ONDO(temperaturo)- iA JOUSHOUSURU(rise)" in Japanese. In order to deted the chain for their topic-dominant chaning relation, we must infor that the rising of temperature produce a heat. Such a problem is ignored in this resentel. 


\section{Conclusion}

We have proposed a method of detecting DS automatically using surface information in sentencesi: che expressions, word/plurase chains, and similarity between sentences. In the case of sciontific and technical texts, consicterable part of the Iss can be estimated hy incor. polating the three types of clue information, without, performing sentence unelerstanding processes which requires giving knowledge to computers. Jhis alpuronch can be smoothly integraled with the current NIP systems dealing witl large anomnts of text.s

\section{References}

Cohen, R. (1984). "A Computational 'T'leomy of the Function of Clue Words in Arguncent. Understanding." In Procedinges of loth colldNe.

Dallgren, K. (1088). Naine Semantics for Natural Language Underslanding. Kluwer Acadenice P'ublishers.

Gros\%, B. J. and Sidner, C. L. (1986), "Allention, Intentions, and the Structures of Discourse." Computational linguistics, 12-3.

IIobbs, J. R. (1985). On the Coherenes and Structure of Discourse. Technical Roport No. CSla-85-37.

Kurohashi, S. and Nagao, M. (1992a), "A Symbelic: Analysis Method of Long Japanese Sentencess based on Cominnetive Structures' Detection." (in

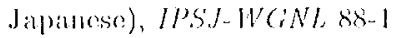

Kunoluashi, S. and Nagno, M. (1952b), "I)yumaic Programming Meblod for Analyzing Conjunctive Structures in Japanese." In Procecdings of $1 / 1 \mathrm{ll}$ COLING

Mann, W. ( . (1981). "Discourse Structures for lext Ciencration." In Procededings of lollh COLINC $i$.

Murata, M. and Nagao, M. (1993). "Doterminaticon of referential property and number of nouns in Japanese sentences for machine transtation into Linglish." [n Procededing.s of Th// 9:3.

Polanyi, L, and Scha, R. (19S1). "A syolactic Approach to Discourse Sombutics." In Procerding of lolh COLINC:

Reichman, R. (1985). Gelling Computers to Talli lide You and Me. Cambridge, MA, 'The Ml'T Press.

Zadrozny, W. and Jensen, K. (1991). "Semantics of" paragraplss." Compulational tingnistics, $17-2$.

\section{Appendix: Sample Text}

Title: Advanced Compuling for Science

(" $i$ " and "j" in si-j denote the seclion nunblere and l.he" sentence number respoctively)

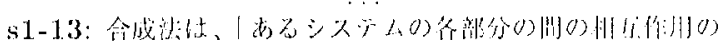

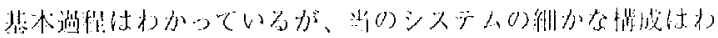

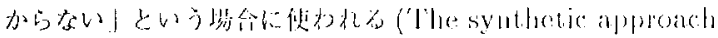
is called for when the fundanental processes of the in teractions annong the parts of a system a re knewh, luth the detailed configuration of the system is not.)

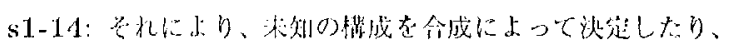

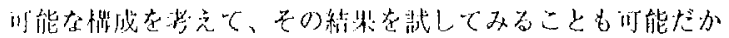
5 configuration by synthesis: one can survey the possible configurations and work out the consequences of each.)

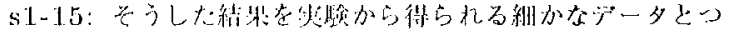

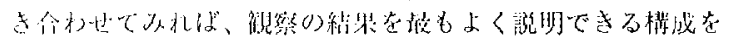

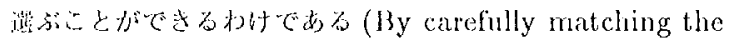
olservalue details of the experimental situation with these conscquences, one can choose the configuration that best accounts lor the observations.)

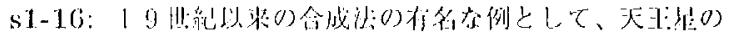

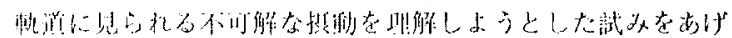

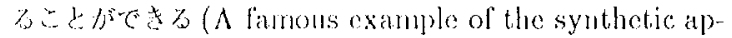
proach from the loth century is the attempt that was mate to maderstand the observed but mexplained per. turbations in the ofdit of Uranus.)

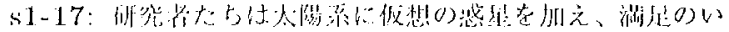

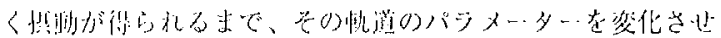
cwot: (Investigitions anded a liypothetical planet to the solar system and varied the parameters of its orbit until a satisfactory reconsiruction of the perturbation was foumel.)

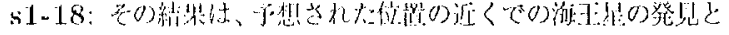

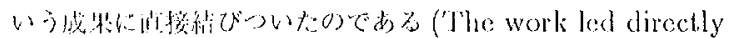
to the discovery of Neptune, found near the predicted position.)

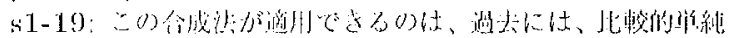

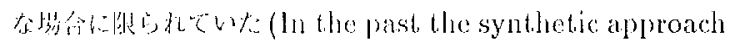
was limited to companatively simple situations. )

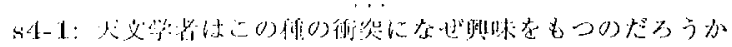
(Why are astronomers interested in this kind of collision?)

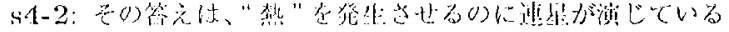
役制传古 ("llye answer lies in the role of double stars in generiating "heal." )

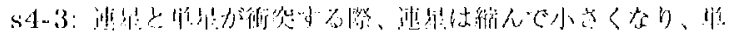

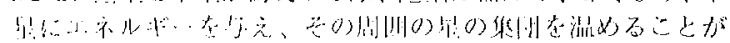
b) (lu a collision between a double star and a single star, lite doulde star can shrink, transformg energy to the single stal and lincroby heating the pool of stars around them.)

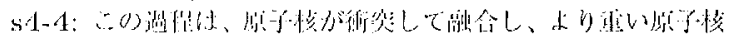

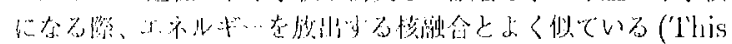
process is analogous to nuclear fusion, wherein atomic muclei collide and fuse iulo leavien nuclej, releasing energy.)

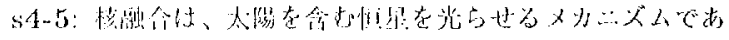
\% (Nuctear fusion is the same phenomenon that makes 1. he stars, including the sun, sline)

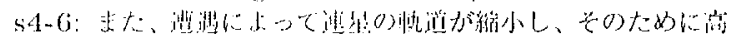

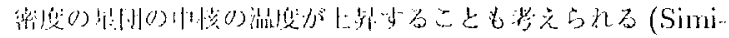
larly, orbital slarinkage of double stars induced by encombers (an heat the core of dense star clusters.)

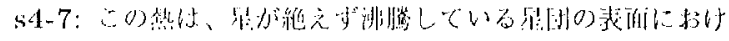

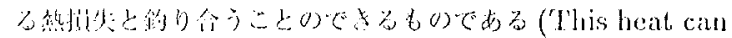
balance the losises at the surface of star clusters, where aties hoil of contimuonsly.) 